\title{
Development of a First-Order Derivative UV Spectrophotometric Method for the Assay and Solubility Evaluation of Lamotrigine and Nicotinamide Cocrystals
}

\author{
Isabela F. B. Biscaia, ${ }^{a}$ Vitor Todeschini, ${ }^{b}$ Rafaela Z. C. de Meira, ${ }^{a}$ Camila Nogueira, ${ }^{a}$ \\ Larissa S. Bernardi ${ }^{a}$ and Paulo R. de Oliveira ${ }^{\circledR} * a$ \\ aPrograma de Pós-Graduação em Ciências Farmacêuticas, Departamento de Farmácia, \\ Universidade Estadual do Centro-Oeste (UNICENTRO), \\ Rua Simeão Camargo Varela de Sá, 03, 85040-080 Guarapuava-PR, Brazil \\ ${ }^{b}$ Faculdade de Farmácia, Universidade Federal do Rio de Janeiro, \\ Rua Aluísio da Silva Gomes, 50, 27930-560 Macaé-RJ, Brazil
}

\begin{abstract}
Pharmaceutical cocrystals are composed of a drug and a coformer and are currently gaining attention due to their possibility of improving drug solubility. Quantitative determination of cocrystals is usually carried out by liquid chromatography method, but an alternative for the same is derivative UV spectrophotometry. Cocrystals of lamotrigine (LAM) were formed with nicotinamide (NIC) in order to improve the solubility of LAM. The aim of this study was to develop and validate a simple, low-cost, environment friendly, first-order derivative spectrophotometric method for simultaneous determination of LAM and NIC in cocrystals. Determination of LAM and NIC was performed at 244.4 and $271.6 \mathrm{~nm}$, respectively. The method was accurate with recovery values of 98.21-101.52\%, and precise (relative standard deviation (RSD) $<1.88 \%$ ). Robustness evaluated by Plackett-Burman design showed no significant influence of the factors ( $\mathrm{pH}$, scanning speed, and sonication time) on LAM and NIC assays. The developed method was compared with a high performance liquid chromatography (HPLC) method and applied to study the cocrystal stoichiometry and solubility. The results indicated a molar ratio of 1:1 and that the cocrystal is more soluble than the drug. This study demonstrated that the first-order derivative method is feasible for drug and coformer determination in cocrystals and is a suitable alternative to chromatographic methods.
\end{abstract}

Keywords: separations, drug design, spectroanalytical, spectrophotometry analysis, method validation

\section{Introduction}

Pharmaceutical cocrystals have been increasingly reported in the pharmaceutical market. They exhibit solid crystalline form and are composed of active pharmaceutical ingredient (API) and a coformer, which can be another drug or a non-toxic molecule in specific stoichiometric amounts. ${ }^{1-3}$ The crystallization process involves nucleation and surface chemistry, forming intermolecular hydrogen bonds between critical sub-structural units ${ }^{4}$ forming a crystal lattice that allow changes in the essential properties of an API without altering its mechanism of action. ${ }^{5}$ The solubility behavior of drugs is one of the most challenging factors in formulation development for oral delivery. ${ }^{6}$ Cocrystals may be a useful tool in this regard, since they

*e-mail: proliveira@unicentro.br can enhance solubility of poorly soluble drugs through the generation of the metastable supersaturated state, which can aid in improving their absorption and bioavailability, without altering the pharmacological effects. ${ }^{7}$

Drugs with poor aqueous solubility may have good pharmacological properties, such as lamotrigine (LAM, Figure 1a), an antiepileptic drug that belongs to the class of phenyltriazines and is used for treating epilepsy and bipolar disorder. LAM, chemically known as [6-(2,3-dichlorophenyl)-1,2,4-triazine-3,5-diamine] is a basic molecule with a $\mathrm{p} K_{\mathrm{a}}$ of $5.7,{ }^{8}$ has low aqueous solubility ${ }^{9}$ and high permeability and is categorized in class II as per the Biopharmaceutics Classification System. ${ }^{10}$

Different crystal engineering strategies have been adopted to obtain new solid forms of LAM in order to increase its solubility. ${ }^{11}$ A better dissolution rate for this drug may increase its bioavailability, and hence reduce 
<smiles>Nc1nnc(-c2cccc(Cl)c2Cl)c(N)n1</smiles>

(a)<smiles>NC(=O)c1cccnc1</smiles>

(b)
Figure 1. Chemical structures of (a) lamotrigine and (b) nicotinamide.

the dose and risk of side effects. In search of these benefits, a cocrystal of LAM with nicotinamide (NIC, Figure $1 \mathrm{~b}$ ), a non-toxic substance with $\mathrm{p} K_{\mathrm{a}} 3.35$ and high aqueous solubility was developed by using reaction crystallization method. ${ }^{12}$ The cocrystal was obtained since in aqueous $\mathrm{pH}$ the neutral form of the components is predominant, generating cocrystallization and preventing ionic interaction.

The quantification of LAM and NIC in cocrystals can be carried out by high performance liquid chromatography (HPLC) methods, ${ }^{13}$ however, this technique requires the expertise and training of analysts, is time-consuming, demands the use of expensive and hazardous chemicals (like acetonitrile and methanol, which are flammable, volatile and toxic), and is not very environment friendly, ${ }^{14,15}$ since mobile phase may be a source of environmental pollution. Generally, HPLC is carried out using a stationary phase column of $4.6 \mathrm{~mm}$ of internal diameter and of $15-25 \mathrm{~cm}$ length with mobile-phase flow rate of about 1-1.5 $\mathrm{mL} \mathrm{min}^{-1}$, leading to huge consumption of solvent and generation of approximately 1.5 to $2 \mathrm{~L}$ of waste daily. ${ }^{16} \mathrm{An}$ alternative involves the use of spectrophotometric techniques, that are preferable for practical and economic reasons and can be good alternatives for quality control analysis. ${ }^{17,18}$

A useful approach for enhancing the sensitivity and selectivity of mixture analysis is derivative spectrophotometry, ${ }^{19}$ a method which involves calculation and plotting one of the mathematical derivatives of a spectral curve, based on zero-crossing measurements. It has been applied in pharmaceuticals mainly for the determination of drugs used in ophthalmic formulations, ${ }^{20}$ extendedrelease tablets, ${ }^{21}$ in bulk powder, ${ }^{22}$ and determination of analytes in biological samples. ${ }^{23}$ The literature ${ }^{24}$ describes only one derivative method considering the assay of cocrystals, applied for the determination of simvastatin in cocrystals formed with saccharin and aspartame, however, the quantification of the coformer was not carried out, not answering the cocrystal stoichiometric question, which is important to predict solubility advantages from the cocrystal eutectic constant.

Considering that simultaneous determination of the drug and the coformer is crucial for cocrystal studies and that there is a limited number of studies regarding the application of derivative spectrophotometric methods for cocrystals assay, the aim of this study was to develop and validate a simple, fast and cost-effective first-order derivative spectrophotometric (FODS) method for the simultaneous determination of LAM and NIC in cocrystals.

\section{Experimental}

Reagents and materials

\section{Pure samples}

LAM was purchased from Fagron (Mumbai, India), 99.89\% purity; NIC was purchased from Sarfam (Shangai, China), 99.70\% purity; and both reagents were used within their shelf life period. Ultrapure water (Merck Millipore, Simplicity System, Darmstadt, Germany) with $\mathrm{pH}$ (pHmeter Edge, Hanna Instruments, Woonsocket, USA) of 6.9 , conductivity of $0.055 \mu \mathrm{S} \mathrm{cm}{ }^{-1}$ and $18.2 \mathrm{M} \Omega \mathrm{cm}$ resistivity, was used for all the analyses.

\section{Cocrystal synthesis}

The cocrystals were developed through the reaction crystallization method, as previously described. ${ }^{13}$ Briefly, $4 \mathrm{~g}$ of NIC was weighed on an analytical balance (Shimadzu, AUX220, Kyoto, Japan) and solubilized in $2 \%(\mathrm{~m} / \mathrm{v})$ sodium lauryl sulfate aqueous solution and maintained on a magnetic stirring plate (Fisatom, 754A, São Paulo, Brazil) at room temperature. Subsequently, $1 \mathrm{~g}$ of LAM was slowly added. After $48 \mathrm{~h}$, the suspension was vacuum filtered, and the solid phase retained on the filter was oven dried at $60{ }^{\circ} \mathrm{C}$ for $2 \mathrm{~h}$. Three different batches of cocrystals were produced and used in this study.

\section{First-order derivative spectrophotometric method}

\section{Preparation of solutions}

Stock standard solutions were prepared by accurately weighing $12.5 \mathrm{mg}$ of LAM and $12.5 \mathrm{mg}$ of NIC, and dissolving them in $500 \mathrm{~mL}$ of water, followed by sonication for $30 \mathrm{~min}$ to facilitate solubilization, thereby obtaining the concentration of $0.025 \mathrm{mg} \mathrm{mL}^{-1}$.

The cocrystal solutions were prepared by dissolving $25 \mathrm{mg}$ of cocrystals in $500 \mathrm{~mL}$ of water, followed by sonication for $30 \mathrm{~min}$ to obtain the concentration of $0.05 \mathrm{mg} \mathrm{mL}^{-1}$. The solutions were diluted to a final theoretical concentration of $20 \mu \mathrm{gL} \mathrm{m}^{-1}$ for the cocrystal for the quantitative determination of LAM and NIC.

\section{Selection of wavelengths}

Spectrophotometric measurements were recorded using water as blank solution on UV-Vis double beam 
spectrophotometer (Agilent Technologies, Cary 100, Santa Clara, USA). Spectra of LAM and NIC solutions were scanned in the spectrum mode between 200 and $400 \mathrm{~nm}$, with a bandwidth of $2 \mathrm{~nm}$ and a scanning speed of $60 \mathrm{~nm} \mathrm{~min}{ }^{-1}$. Each spectrum was derived mathematically from zero-order to the first-order by software (Cary WinUV, version 4.20), with the tool "maths", operation "Deriv 1", filter size 9, and interval 4. The first-order derivative spectra for LAM and NIC were overlapped to find the wavelength at which each drug shows zero absorbance. The wavelength of $244.4 \mathrm{~nm}$ was selected for the quantification of LAM (where the derivative response for NIC was zero). Similarly, $271.6 \mathrm{~nm}$ was selected for the quantification of NIC (where the derivative response for LAM was zero).

Method validation

The method was validated following the guidelines of the International Conference on Harmonization (ICH). ${ }^{25}$

\section{Selectivity}

The selectivity was evaluated by the analysis of LAM at the wavelength used for the quantification of the NIC and vice versa.

\section{Linearity}

Linearity was determined by plotting three independent analytical curves, each one containing five concentrations of both LAM and NIC, in the range of 2.5-20 $\mu \mathrm{g} \mathrm{mL}^{-1}(2.5,5$, 10,15 , and $20 \mu \mathrm{g} \mathrm{mL}^{-1}$ ) versus the values of the first-order derivative absorbance (at $244.4 \mathrm{~nm}$ for LAM and at $271.6 \mathrm{~nm}$ for NIC). The linearity was evaluated by the least square regression analysis and analysis of variance (ANOVA).

\section{Precision}

The precision of the analytical methods was evaluated by analyzing the repeatability and the intermediate precision measurements of the cocrystal solutions. Repeatability was examined by assaying six independent sample preparations on the same day (intra-day), at the same concentration $\left(20 \mu \mathrm{g} \mathrm{mL}^{-1}\right.$ ) of cocrystals (corresponding to $13.5 \mu \mathrm{g}$ of LAM and $6.5 \mu \mathrm{g}$ of NIC) under the same experimental conditions. The inter-day precision was calculated by comparing the results of three consecutive days, and the inter-analyst precision was obtained by comparing the results of three different analysts. The precision was expressed in terms of relative standard deviation (RSD).

\section{Accuracy}

The degree of accuracy was calculated in triplicates and was based on the percentage of recovery of the known amounts of LAM and NIC added to the cocrystal samples. Suitable volumes of the standard solutions of LAM $\left(5 \mu \mathrm{g} \mathrm{mL}^{-1}\right)$ and NIC $\left(5 \mu \mathrm{g} \mathrm{mL}^{-1}\right)$ were added to the cocrystal samples to obtain the solutions at final concentrations of 8,10 , and $12 \mu \mathrm{g} \mathrm{mL}^{-1}$ for LAM and 8,10 , and $12 \mu \mathrm{g} \mathrm{mL}^{-1}$ for NIC.

Limit of detection (LOD) and limit of quantification (LOQ)

The limits were calculated from the three calibration curves used in the linearity, in accordance with the following equations 1 and 2 :

$\mathrm{LOD}=\frac{3.3 \mathrm{SD}_{\mathrm{b}}}{\mathrm{a}}$

$\mathrm{LOQ}=\frac{10 \mathrm{SD}_{\mathrm{b}}}{\mathrm{a}}$

where $\mathrm{SD}_{\mathrm{b}}$ represents the standard deviation of the $y$-intercept and $\mathrm{a}$ is the mean slope of the calibration curve.

\section{Robustness}

The robustness was investigated analyzing changes that may occur in the laboratory routine, due to small differences in the calibration or programming of the equipment by the user, by the influence of the factors: $(i) \mathrm{pH}$ of water $(6.9 \pm 0.2)$, (ii) scanning speed $\left(60 \pm 20 \mathrm{~nm} \mathrm{~min}^{-1}\right)$, and (iii) sonication time in solution preparation $(30 \pm 5 \mathrm{~min})$ on the spectrophotometric response for LAM and NIC assay. Robustness was analyzed by Plackett-Burman method, because an experimental design is preferred since the response results from a combination of factors, representing more globally the practical situation in the laboratory. The designs were constructed as described by Plackett and Burman, ${ }^{26}$ the first line for the designs with $\mathrm{N}=12, \mathrm{~N}$ being the number of experiments and (+) and (-) the levels of the factors. After determination of the number of real factors to be examined, the remaining columns in the design were defined as dummy factors, an imaginary factor for which the change from one level to the other has no physical meaning, used for estimating the standard error. The results were evaluated by $t$-test, and an effect is considered significant at a given a level if $t_{\text {calculated }}>t_{\text {critical }}$.

\section{Application of the method}

The analysis of cocrystals $\left(20 \mu \mathrm{g} \mathrm{mL}^{-1}\right)$ from three different lots was performed in triplicate. The average was obtained, and the result of the derivative absorbance was applied in the linearity equation to evaluate the concentrations of LAM and 
NIC in the cocrystal. Subsequently, molar stoichiometry was calculated by the relation with the respective molar masses $\left(\mathrm{LAM}=256.91 \mathrm{~g} \mathrm{~mol}^{-1}\right)$ and $\left(\mathrm{NIC}=122.12 \mathrm{~g} \mathrm{~mol}^{-1}\right)$. The results obtained by the FODS method were statistically (Student's $t$-test) compared with those obtained by a previously validated HPLC method (Shimadzu, CTO-20A, Kyoto, Japan). Shortly, the HPLC method for LAM consisted of a Luna ${ }^{\circledR} \mathrm{C} 18150 \times 4.6 \mathrm{~mm}$ column, mobile phase composed of $0.01 \mathrm{M}$ methanol:phosphate buffer, $\mathrm{pH} 3.5$ $(40: 60, \mathrm{v} / \mathrm{v})$, flow rate $1.0 \mathrm{~mL} \mathrm{~min}{ }^{-1}$, detection wavelength of $279 \mathrm{~nm}$, injection volume $10 \mu \mathrm{L}$, temperature $30^{\circ} \mathrm{C}$, and run time of $6.5 \mathrm{~min}$. For quantification of NIC, the mobile phase was modified to $0.01 \mathrm{M}$ methanol:phosphate buffer pH $3.5(15: 85, \mathrm{v} / \mathrm{v})$; wavelength of $261 \mathrm{~nm}$, and the run time was changed to $4.5 \mathrm{~min}$.

The determination of eutectic constant $\left(\mathrm{K}_{\mathrm{eu}}\right)$ was performed to predict cocrystal solubility and stability. In $10 \mathrm{~mL}$ of water, $1 \mathrm{~g}$ of cocrystal was added and kept under stirring at $110 \mathrm{rpm}$ at room temperature $\left(25^{\circ} \mathrm{C}\right)$. After $48 \mathrm{~h}$, aliquots were removed and API and coformer concentration values in the eutectic point were determined and applied to the $\mathrm{K}_{\mathrm{eu}}$ equation (equation 3 ). ${ }^{27}$

$\mathrm{K}_{\mathrm{eu}}=\frac{[\text { coformer }]_{\mathrm{eu}}}{[\mathrm{API}]_{\mathrm{eu}}}$

\section{Results and Discussion}

\section{Method development}

Water was selected as the solvent for all stages of sample preparation, because it is the best solvent considering the toxicological risks, the requirement of special residue storage, and the cost. The overlay of the zero-order UV spectra of LAM and NIC is shown in Figure 2a and shows maximum absorption wavelengths in water at 302.6 and $262.2 \mathrm{~nm}$, respectively. However, it was impossible to determine the two compounds simultaneously by direct absorbance measurements due to the significant overlap between the two spectra.

Derivative spectrophotometry can be a suitable technique for overcoming this situation, as it allows simultaneous measurement of both elements and prevents interference with each other. ${ }^{14}$ Figure $2 b$ shows that the zero-crossing points were $244.4 \mathrm{~nm}$ for NIC and $271.6 \mathrm{~nm}$ for LAM and no mutual interference was observed. Thus, these wavelengths were selected for determination of the compounds.

\section{Method validation}

Selectivity studies showed that the components did not show cross-interference during the analysis. LAM and NIC showed zero absorbance at 271.6 and $244.4 \mathrm{~nm}$, respectively.

Linearity shows the ability of the method to provide results that are directly proportional to the concentration of the analyte in the sample. Linearity was within the suitable range for the instrument, as can be seen by the zero-order (Figure 3a) and the first-order spectra (Figure $3 b$ ) that contained increasing amounts of a mixture of LAM and NIC. The calibration curve indicated good linearity, with correlation coefficients of $\mathrm{r}^{2}=0.9999$ $(y=0.000990 x-0.000151)$ for LAM and $\mathrm{r}^{2}=0.9999$ $(y=0.001529 x-0.000015)$ for NIC. Moreover, ANOVA $(\alpha=0.05)$ was performed to determine if the linear method had the best fit and the results showed significant linear regression $(P<0.05)$ and no deviation from linearity
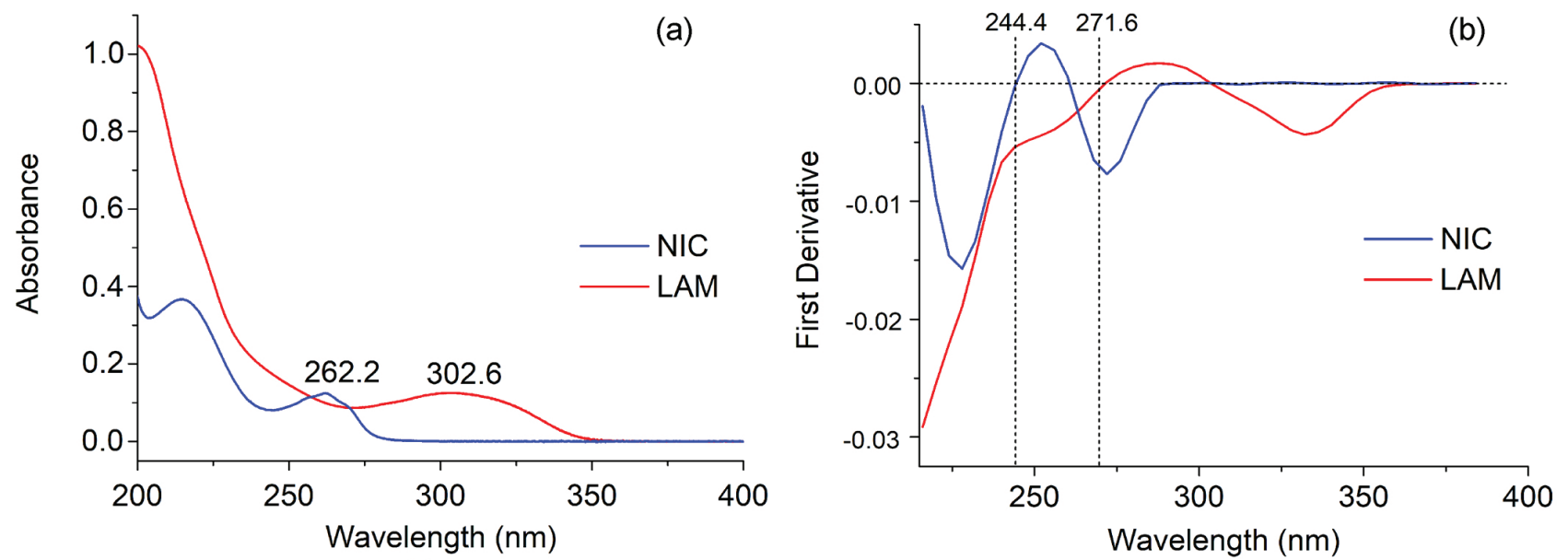

Figure 2. (a) Zero-order spectra of lamotrigine and nicotinamide in water, with a bandwidth of $2 \mathrm{~nm}$ and a scanning speed of $60 \mathrm{~nm}$ min ${ }^{-1}$, compared to a reagent blank; (b) first-order derivative spectra of lamotrigine and nicotinamide, derived mathematically by software of the equipment, operation "Deriv 1", filter size 9, and interval 4. 

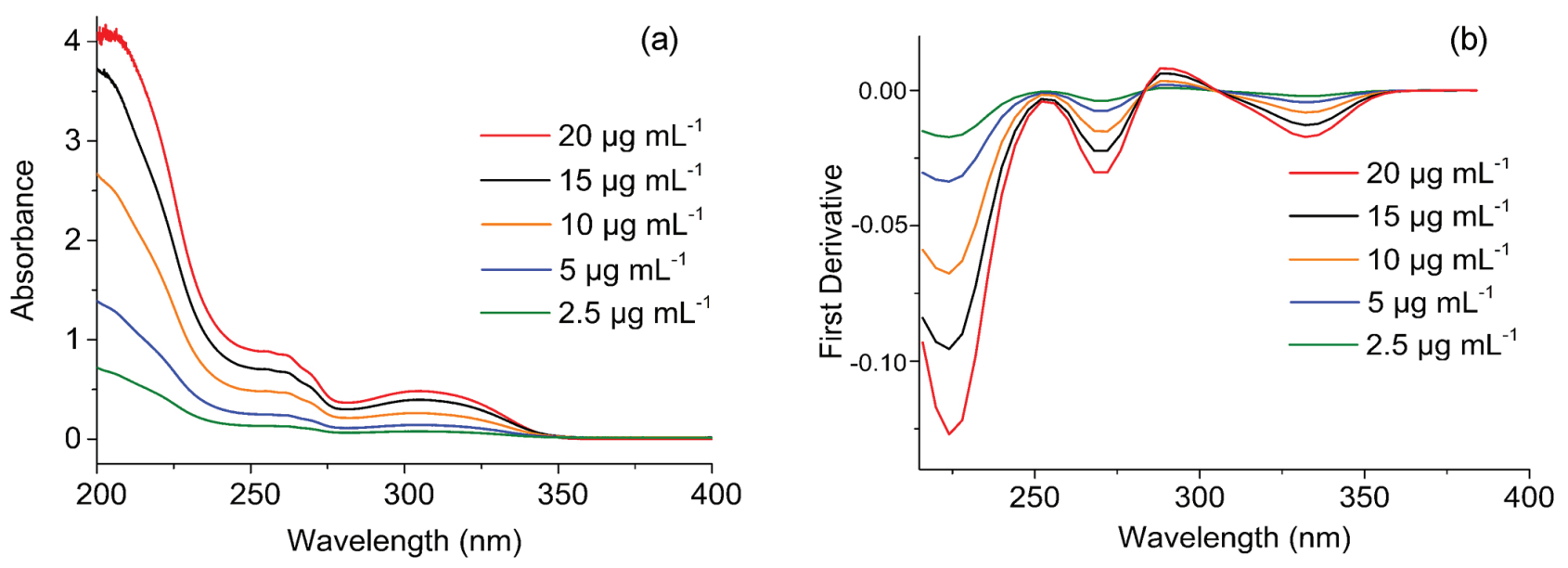

Figure 3. (a) Zero-order spectra of the analytical curves of lamotrigine and nicotinamide in water, with a bandwidth of $2 \mathrm{~nm}$ and a scanning speed of $60 \mathrm{~nm} \mathrm{~min}{ }^{-1}$, compared to a reagent blank; (b) first-order derivative spectra of the analytical curves of lamotrigine and nicotinamide derived mathematically by software of the equipment, operation "Deriv 1", filter size 9, and interval 4.

for LAM $\left(F_{\text {calculated }}=0.26<F_{\text {critical }}=3.71\right)$ or for NIC $\left(F_{\text {calculated }}=1.21<F_{\text {critical }}=3.71\right)$.

Precision refers to the closeness of agreement between the varied measurements obtained from multiple sampling of the same sample under the prescribed conditions. ${ }^{25}$ For reproducibility $(\mathrm{n}=6)$, the RSD value obtained was $1.88 \%$ (mean assay value $=100.22 \%$ ) for LAM and $0.90 \%$ (mean assay value $=100.72 \%$ ) for NIC. The RSD values obtained for inter-day precision were $0.56 \%$ (mean assay value $=101.23 \%$ ) for LAM and $1.23 \%$ (mean assay value $=100.31 \%$ ) for NIC. The RSD values obtained for inter-analyst precision were $0.90 \%$ (mean assay value $=100.56 \%$ ) for LAM and $0.77 \%$ (mean assay value $=100.31 \%$ ) for NIC. The variability of the results was low, with RSD values observed within the acceptable range $(<2 \%)$, which confirmed the precision of the proposed method.

The accuracy of a method is expressed in terms of the closeness of agreement between the value that is accepted as a reference-point and the result obtained by the proposed method. ${ }^{25}$ The results were expressed as the percentage of the LAM and NIC reference substances recovered from the sample and are shown in Table 1 . The mean recovery data, which comprises the three levels added, were within 98.87 and $100.34 \%$, which confirms that the method is accurate within the desired range.

The LOD of an analytical procedure is the lowest amount of an analyte in a sample which can be detected, and the LOQ is the lowest amount of an analyte in a sample which can be quantitatively determined..$^{25}$ These parameters are not an essential requirement in the method validation applied for the drug assay, although it is useful to show the sensitivity of the method and that the analysis is being conducted with a suitable range of concentrations. The results for LOD and LOQ were 0.24 and $0.80 \mu \mathrm{g} \mathrm{mL}^{-1}$ for LAM and 0.024 and $0.080 \mu \mathrm{g} \mathrm{mL} \mathrm{m}^{-1}$ for NIC, respectively. These values showed that the proposed method presented good sensitivity in theory, however, to ensure the linearity of the method, the experimental values must be within the linearity curve, that is, at least $2.5 \mu \mathrm{g} \mathrm{mL} \mathrm{m}^{-1}$.

Robustness is a measure of the ability of the method to be unaffected by small and deliberate variations in its

Table 1. Experimental values obtained in the recovery test for LAM and NIC by using the first-order derivative spectrophotometric method. The standard concentration refers to pure samples of LAM and NIC, while the sample concentration refers to cocrystal

\begin{tabular}{lccccc}
\hline Analyte & $\begin{array}{c}\text { Sample concentration / } \\
\left(\mu \mathrm{g} \mathrm{mL}^{-1}\right)\end{array}$ & $\begin{array}{c}\text { Standard concentration } \\
\text { added / }\left(\mu \mathrm{gL}^{-1}\right)\end{array}$ & $\begin{array}{c}\text { Mean concentration } \\
\text { found } /\left(\mu \mathrm{gL}^{-1}\right)\end{array}$ & $\begin{array}{c}\text { Mean standard } \\
\text { recovered }^{\mathrm{a}} /\left(\mu \mathrm{mL}^{-1}\right)\end{array}$ & $\begin{array}{c}\text { Accuracy } \pm \mathrm{RSD}^{\mathrm{a}} / \% \\
\text { LAM }\end{array}$ \\
LAM & 6.64 & 2 & 8.65 & 2.01 & $100.34 \pm 1.27$ \\
LAM & 6.64 & 4 & 10.62 & 3.97 & $99.24 \pm 0.25$ \\
NIC & 6.64 & 6 & 12.61 & 5.96 & $99.33 \pm 0.90$ \\
NIC & 4.41 & 4 & 8.37 & 3.95 & $98.87 \pm 0.67$ \\
NIC & 4.41 & 6 & 10.35 & 5.94 & $98.98 \pm 0.77$ \\
\hline
\end{tabular}

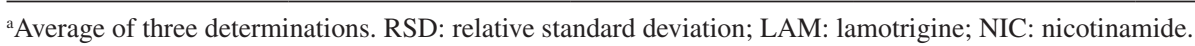


parameters, an indicator of the method reliability during use. ${ }^{25}$ The factors studied were chosen based on small and deliberate changes that may affect the methodology, such as: $\mathrm{pH}$ change may affect the absorbance spectra, ${ }^{28}$ sonication time can interfere in sample preparation and scanning speed can generate different spectra resolutions.

The factors were examined in a Plackett-Burman experimental design, selected as a function of the number of factors under investigation. This design allows to screen a relatively large number of factors in a relatively small number of experiments. ${ }^{29}$ The results are demonstrated in Table 2 and the method was considered robust since the assay was between 98.82 and $101.90 \%$ for LAM and between 98.52 and $102.28 \%$ for NIC. Statistical analysis using $t$-test showed that no significant factor was revealed for all analyses, since the calculated $t$ values were lower than the critical $t$ values $(\alpha=0.05)$.

\section{Application of the method}

The assay for three different batches of cocrystals (Table 3 ) showed a mean concentration of $12.66 \pm 0.51 \mu \mathrm{g} \mathrm{mL}-1$ for LAM, indicating a presence of 0.05 moles in each sample. The mean concentration of NIC was observed to be $6.63 \pm 0.15 \mu \mathrm{g} \mathrm{mL} L^{-1}$, also indicating the presence of 0.05 mol. Approximately $66 \%$ of the cocrystal composition coincided with LAM, while $33 \%$ of the composition showed NIC, which is justified by the fact that the molar mass of LAM is approximately twice that of NIC. Hence the, the cocrystal stoichiometry was noted to be 1:1, drug:coformer.

The proposed FODS method was compared to a validated HPLC method (Table 3). Statistical analysis indicated that the results were similar and showed no significant differences between the methodologies $(P<0.05)\left(F_{\text {calculated }}=0.0023<F_{\text {critical }}=2.306\right.$ for NIC and $F_{\text {calculated }}=6.46 \times 10^{-7}<F_{\text {critical }}=2.306$ for LAM). The results showed that FODS method was suitable for the simultaneous determination of LAM and NIC in cocrystals. A disadvantage of the HPLC was that two methods were necessary for LAM and NIC assay because drug and coformer present distinct characteristics, such as polarity and $\mathrm{p} K_{\mathrm{a}} \cdot{ }^{30}$ These differences require the analyst to develop two different methods or work with solvent gradient, which, in both cases, will be more expensive, time consuming and not environmentally friendly compared to derivative UV spectrophotometric methods.

The simultaneous quantification of LAM and NIC would not be possible based on a maximum wavelength determination of each substance (classical

Table 2. Plackett-Burman experimental design with the obtained response to each experiment and the effects of the investigated factors

\begin{tabular}{|c|c|c|c|c|c|c|c|c|c|c|c|c|c|}
\hline \multirow{2}{*}{ Experiment } & \multirow{2}{*}{$\begin{array}{l}\mathrm{pH} \text { of } \\
\text { water }\end{array}$} & \multirow{2}{*}{ Dummy } & \multirow{2}{*}{ Dummy } & \multirow{2}{*}{$\begin{array}{l}\text { Sonication } \\
\text { time }\end{array}$} & \multirow{2}{*}{ Dummy } & \multirow{2}{*}{ Dummy } & \multirow{2}{*}{ Dummy } & \multirow{2}{*}{ Dummy } & \multirow{2}{*}{$\begin{array}{c}\text { Scanning } \\
\text { speed }\end{array}$} & \multirow{2}{*}{ Dummy } & \multirow{2}{*}{ Dummy } & \multicolumn{2}{|c|}{ Assay / \% } \\
\hline & & & & & & & & & & & & LAM & NIC \\
\hline 1 & + & + & - & + & + & + & - & - & - & + & - & 100.90 & 98.60 \\
\hline 2 & - & + & + & - & + & + & + & - & - & - & + & 101.75 & 99.09 \\
\hline 3 & + & - & + & + & - & + & + & + & - & - & - & 101.83 & 98.52 \\
\hline 4 & - & + & - & + & + & - & + & + & + & - & - & 101.90 & 99.15 \\
\hline 5 & - & - & + & - & + & + & - & + & + & + & - & 99.51 & 100.10 \\
\hline 6 & - & - & - & + & - & + & + & - & + & + & + & 99.51 & 100.10 \\
\hline 7 & + & - & - & - & + & - & + & + & - & + & + & 98.87 & 102.36 \\
\hline 8 & + & + & - & - & - & + & - & + & + & - & + & 100.90 & 98.60 \\
\hline 9 & + & + & + & - & - & - & + & - & + & + & - & 98.82 & 102.28 \\
\hline 10 & - & + & + & + & - & - & - & + & - & + & + & 99.46 & 100.05 \\
\hline 11 & + & - & + & + & + & - & - & - & + & - & + & 98.82 & 102.28 \\
\hline 12 & - & - & - & - & - & - & - & - & - & - & - & 101.90 & 99.15 \\
\hline $\mathrm{E}(\mathrm{LAM}) / \%$ & -0.65 & 0.44 & -0.63 & 0.11 & -0.11 & 0.77 & 0.20 & 0.13 & -0.87 & -1.67 & -0.93 & -0.65 & 0.44 \\
\hline $\mathrm{E}(\mathrm{NIC}) / \%$ & 0.83 & -0.42 & 0.73 & -0.48 & 0.48 & -1.70 & 0.45 & -0.45 & 0.79 & 1.12 & 0.78 & 0.83 & -0.42 \\
\hline$t_{\text {calc }}(\mathrm{LAM})$ & -0.83 & & & -0.14 & & & & & 1.12 & & & & \\
\hline$t_{\text {calc }}(\mathrm{NIC})$ & 0.95 & & & 0.55 & & & & & -0.90 & & & & \\
\hline$t_{\text {crit }}$ & 2.306 & & & & & & & & & & & & \\
\hline
\end{tabular}

Assay: quantitative determination of lamotrigine and nicotinamide; LAM: lamotrigine; NIC: nicotinamide; (+) high factor level: for pH 7.1, scanning speed: $80 \mathrm{~nm} \mathrm{~min}{ }^{-1}$, sonication time: $35 \mathrm{~min}$; (-) low factor level: for $\mathrm{pH}$ 6.7, scanning speed: $40 \mathrm{~nm} \mathrm{~min}{ }^{-1}$, sonication time: 25 min; E: calculated effects for quantitative determination. 
Table 3. Assay of the cocrystals by the FODS method and comparison with HPLC methodology

\begin{tabular}{|c|c|c|c|c|c|c|}
\hline \multirow{2}{*}{ Analyte } & \multicolumn{2}{|c|}{ Concentration $^{\mathrm{a}} /\left(\mu \mathrm{g} \mathrm{mL}^{-1}\right)$} & \multicolumn{2}{|c|}{ Molarity / mol } & \multicolumn{2}{|c|}{ Mean $\pm \operatorname{RSD}^{\mathrm{a}} / \%$} \\
\hline & FODS & HPLC & FODS & HPLC & FODS & HPLC \\
\hline LAM cocrystal, lot 1 & 12.60 & 12.37 & 0.05 & 0.05 & $62.9 \pm 0.56$ & $61.8 \pm 0.14$ \\
\hline LAM cocrystal, lot 2 & 12.67 & 12.49 & 0.05 & 0.05 & $63.3 \pm 0.39$ & $62.4 \pm 0.30$ \\
\hline LAM cocrystal, lot 3 & 12.73 & 12.43 & 0.05 & 0.05 & $63.6 \pm 0.08$ & $62.2 \pm 0.24$ \\
\hline NIC cocrystal, lot 1 & 6.64 & 6.56 & 0.05 & 0.05 & $33.2 \pm 0.11$ & $32.7 \pm 0.33$ \\
\hline NIC cocrystal, lot 2 & 6.62 & 6.57 & 0.05 & 0.05 & $33.1 \pm 0.15$ & $32.8 \pm 0.44$ \\
\hline NIC cocrystal, lot 3 & 6.63 & 6.43 & 0.05 & 0.05 & $33.1 \pm 0.20$ & $32.2 \pm 0.53$ \\
\hline
\end{tabular}

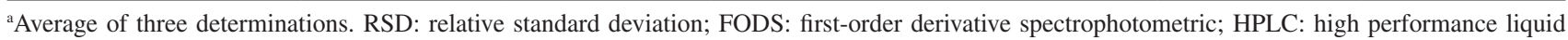
chromatography; LAM: lamotrigine; NIC: nicotinamide.

UV determination) because LAM has an overlapping spectrum with the coformer NIC. So, the development of this methodology is essential for the quantification of the components in cocrystal by UV spectrophotometry.

The stoichiometry information of the cocrystal is necessary to associate this value with the eutectic constant $\left(\mathrm{K}_{\mathrm{eu}}\right)$, an important indicator of the stability and solubility of the cocrystal. $\mathrm{K}_{\mathrm{eu}}$ values $>1$ or $\mathrm{K}_{\mathrm{eu}}>0.5$, for cocrystals $1: 1$ and 2:1, respectively, indicate thermodynamic instability of the cocrystal, but greater solubility in relation to the API, while $K_{\mathrm{eu}}$ values $<1$ or $<0.5$ for cocrystals 1:1 and 2:1, respectively, indicate higher thermodynamic stability and lower solubility of the cocrystal in relation to the API. ${ }^{31}$

The $\mathrm{K}_{\mathrm{eu}}$ was calculated according to equation 3 and a value of 186 was obtained, by dividing 269.85 (coformer concentration at eutectic point) by 1.45 (API concentration at eutectic point). This result indicates that the cocrystal is more soluble and less stable than API. The reason that the value is much higher than 1 is related to the advantage of cocrystal solubility over the drug, the higher the $\mathrm{K}_{\mathrm{eu}}$ value, the greater this advantage. ${ }^{31}$

Additionally, in cocrystals initial development it is usual to perform a screening with several coformers in order to evaluate which one increases the solubility of the API. The FODS method is an easy methodology that quantifies the components of the cocrystals, supporting the choice of the coformer for further studies.

\section{Conclusions}

Assays for multiple compound samples, such as cocrystals, are usually carried out by chromatographic methods, such as HPLC. In this study, a first-order derivative spectrophotometric method was successfully developed and validated for the simultaneous determination of LAM and NIC in cocrystals, with benefits from both economic and ecological point of view. The method proved to be selective, linear, precise, accurate, sensitive, robust, and similar to the HPLC method, showing no significant differences. The analysis of the LAM-NIC cocrystals showed a 1:1 stoichiometry, and the $\mathrm{K}_{\mathrm{eu}}$ calculation evidenced that cocrystal is more soluble and could be less stable than the LAM drug, demonstrating the applicability of derivative spectrophotometric methods in cocrystal studies.

\section{Acknowledgments}

This study was financed in part by the Coordenação de Aperfeiçoamento de Pessoal de Nível Superior, Brazil (CAPES) (Coordination for the Improvement of Higher Education Personnel) finance code 001. The authors would also like to thank Fundação Araucária (Araucária Foundation) and Secretaria de Estado da Ciência, Tecnologia e Ensino Superior do Paraná (SETI) (Secretary of State for Science, Technology and Higher Education in the State of Paraná) for their financial support.

\section{Author Contributions}

Isabela F. B. Biscaia was responsible for the data curation, formal analysis, funding acquisition and writing original draft; Vitor Todeschini for the software and conceptualization; Rafaela Z. C. de Meira for the validation and data curation; Camila Nogueira for the validation; Larissa S. Bernardi for the investigation and visualization; Paulo R. de Oliveira for the project administration, writing review, editing and conceptualization.

\section{References}

1. Qiao, N.; Li, M.; Schlindwein, W.; Malek, N.; Davies, A.; Trappitt, G.; Int. J. Pharm. 2011, 419, 1.

2. Aakeröy, C. B.; Salmon, D. J.; CrystEngComm 2005, 7, 439.

3. Shaikh, R.; Singh, R.; Walker, G. M.; Croker, D. M.; Trends Pharmacol. Sci. 2018, 39, 1033. 
4. Bavishi, D. D.; Borkhataria, C. H.; Prog. Cryst. Growth Charact. Mater. 2016, 62, 1.

5. Berry, D. J.; Steed, J. W.; Adv. Drug Delivery Rev. 2017, 117, 3.

6. Eleamen, G. R. A.; da Costa, S. C.; Lima-Neto, R. G.; Neves, R. P.; Rolim, L. A.; Rolim-Neto, P. J.; Moura, R. O.; de Aquino, T. M.; Bento, E. S.; Scotti, M. T.; Mendonça-Junior, F. J. B.; Mendonça, E. A. M.; Oliveira, E. E.; J. Braz. Chem. Soc. 2017, 28, 116.

7. Kuminek, G.; Cavanagh, K. L.; Rodríguez-Hornedo, N. In Pharmaceutical Crystals: Science and Engineering; Li, T.; Mattei, A., eds.; John Wiley \& Sons: MI, USA, 2018, p. 223-271.

8. Chadha, R.; Saini, A.; Khullar, S.; Jain, D. S.; Mandal, S. K.; Row, T. N. G.; Cryst. Growth Des. 2013, 13, 858.

9. Bolla, G.; Nangia, A.; Chem. Commun. 2016, 52, 8342.

10. Singh, J.; Garg, R.; Gupta, G. D.; J. Pharm. 2015, $2015,828453$.

11. Du, S.; Wang, Y.; Wu, S.; Yu, B.; Shi, P.; Bian, L.; Zhang, D.; Hou, J.; Wang, J.; Gong, J.; Eur. J. Pharm. Sci. 2017, 15, 19.

12. Rodríguez-Hornedo, N.; Nehm, S. J.; Seefeldt, K. F.; Pagán-Torres, Y.; Falkiewicz, C. J.; Mol. Pharm. 2006, 3, 362.

13. Cavanagh, K. L.; Maheshwari, C.; Rodríguez-Hornedo, N.; J. Pharm. Sci. 2018, 107, 113.

14. Todeschini, V.; Barden, A. T.; Sfair, L. L.; Sangoi, S.; Volpato, N. M.; Acta Chim. Slov. 2013, 60, 335.

15. Korany, M. A.; Mahgoub, H.; Haggag, R. S.; Ragab, M. A. A.; Elmallah, O. A.; J. Liq. Chromatogr. Relat. Technol. 2017, 40, 839.

16. Dong, M. W.; Modern HPLC for Practicing Scientists, $1^{\text {st }}$ ed.; Wiley-Interscience: Hoboken, New Jersey, USA, 2006.

17. Maleque, M.; Hasan, M. R.; Hossen, F.; Safi, S.; J. Pharm. Anal. 2012, 2, 454.

18. Kaur, M.; Kaur, V.; Malik, A. K.; Verma, N.; Singh, B.; Rao, A. L. J.; J. Braz. Chem. Soc. 2009, 20, 993.
19. Li, Z.; Wang, Q.; Lv, J.; Ma, Z.; Yang, L.; Appl. Spectrosc. 2015 , 69, 721.

20. Sversut, R. A.; Alcântara, I. C.; Rosa, A. M.; Baroni, A. C. M.; Rodrigues, P. O.; Singh, A. K.; Amaral, M. S.; Kassab, N. M.; Arabian J. Chem. 2017, 10, 604.

21. Sangoi, M. S.; Todeschini, V.; Steppe, M.; Acta Chim. Slov. 2012, 59, 136.

22. Ali, O. I. M.; Ismail, N. S.; Elgohary, R. M.; Spectrochim. Acta, Part A 2016, 153, 605.

23. Ali, N.; Ismail, M.; Khan, A.; Khan, H.; Haider, S.; Kamal, T.; Spectrochim. Acta, Part A 2018, 189, 110.

24. Sopyan, I.; Fudhloli, A.; Muchtaridi, M.; Sari, I. P.; Permatasari, D.; Int. J. Res. Pharm. Sci. 2016, 7, 301.

25. International Conference on Harmonisation of Technical Requirements for Registration of Pharmaceuticals for Human Use (ICH); Validation of Analytical Procedures: Text and Methodology Q2(R1); ICH: London, 2005. Available at http:// academy.gmp-compliance.org/guidemgr/files/Q2(R1).pdf, accessed in June 2020.

26. Plackett, R. L.; Burman, J. P.; Biometrika 1946, 33, 305.

27. Good, D. J.; Rodríguez-Hornedo, N.; Cryst. Growth Des. 2010 , $10,1028$.

28. Owen, T.; Fundamentals of UV-Visible Spectroscopy; HewlettPackard: Germany, 1996.

29. Vander Heyden, Y.; Nijhuis, A.; Smeyers-Verbeke, J.; Vandeginste, B. G. M.; Massart, D. L.; J. Pharm. Biomed. Anal. 2001, 24, 723.

30. Fukte, S. R.; Wagh, M. P.; Rawat, S.; Int. J. Pharm. Pharm. Sci. 2014, 6, 9 .

31. Good, D. J.; Rodríguez-Hornedo, N.; Cryst. Growth Des. 2009 , 9, 2255.

Submitted: March 14, 2020

Published online: July 3, 2020 